\title{
Research on the dynamic relationship between listed company team and social financing scale: based on VAR model
}

\author{
Chen Mengdong ${ }^{1}$ and Wang Lijun ${ }^{1,2}$ \\ ${ }^{1}$ Hubei University of Technology, School of Economics and Management, 430068, wuhan, China \\ ${ }^{2}$ Huazhong Agricultural University, School of Economics and Management, 430068, wuhan, China
}

\begin{abstract}
Social financing scale is an important indicator reflecting financial services to the real economy. This paper uses the VAR model to explore the dynamic relationship between the ranks of listed companies and the scale of social financing. The empirical results show that: There is a long-term equilibrium relationship between the number of listed companies and the scale of social financing, which can boost the expansion of the scale of social financing, but the expansion of the ranks of listed companies has no obvious effect on the immediate boost of the scale of social financing. The "increase in the number" of listed companies in China may imply "low quality". The number of listed companies has a delayed effect on the scale of social financing. In the long run, the expansion of the ranks of listed companies does.
\end{abstract}

\section{1 introduction}

The scale of social financing is a major innovation in China's monetary policy theory and macro-control practice. It is an important indicator connecting finance with the real economy (Li Yuan, 2020) $)^{[1]}$, and can accurately reflect the strength of financial support to the real economy (Liu Xiaoyu, 2019) ${ }^{[2]}$. Improve the entity industry economic development is to enhance the most important driver of China's overall national economic strength, at the right guide financial services in the real economy, providing diversified financing channels, control the scale of social financing reasonable growth, pay attention to the social financing structure optimization is a valid path selection (Liu Dehong liu, $2020)^{[3]}$. During the period of the 13th Five-Year Plan, China's financial market has made a major breakthrough and developed rapidly. The multi-level capital market is more perfect, the financial environment is more open, and enterprises are constantly guided, encouraged and supported to get listed. Under the favorable policy environment and market environment, the ranks of listed companies continue to grow. It plays an irreplaceable role in broadening financing channels, improving financing structure and expanding social financing scale. The scale of social financing is an innovative indicator with Chinese characteristics, which refers to the amount of funds obtained by the real economy from the financial system.

Under the background that finance returns to its source and serves the real economy, it is particularly important to study the indicators of the scale of social financing in China (Zhang Zhe, 2019) ${ }^{[5]}$. The purpose of this paper is to study the ranks of the listed company's growing role of social financing scale, quantity and scale of social financing of listed companies from the inquiry whether there is a certain correlation between and how to according to the correlation of the ranks of the empirical analysis of listed companies of growing whether can boost social financing scale expansion, delving into the booster path and booster. Due to the number of listed companies at the present stage and social financing scale between the research has not yet been relatively consistent conclusion, this article will use the VAR model, will all variables as an endogenous variable, equal treatment, initial coefficient of the model does not impose any constraints, in each of the model equations, the endogenous variable of the model to return all the endogenous variable of lag. Thus, the dynamic correlation between the growth of listed companies and the scale of social financing is estimated.

\section{Model establishment}

\subsection{Index selection and data description}

This paper selects the monthly data of the number of listed companies (represented by $\mathrm{CN}$ ) and the scale of social financing (represented by SF) from January 2012 to October 2020 to study the dynamic correlation between the number of listed companies and the scale of social financing. All data in this paper are from EPS database.

\subsection{Time sequence diagram analysis}

From the point of the sequence diagram of two variables, two time series on the whole their respective paths are not completely the same, the rising trend of $\mathrm{CN}$ is more 
clear, SF, rising trend is not obvious and present certain periodic trends, it is associated with the way of data selection, this article selects the monthly inventory data of social financing scale to do seasonal factors, However, it can also be seen from the cycle peak that the scale of social financing has shown a fluctuating growth trend in the past 18 years, and the range of fluctuation tends to increase. This indicates that the growth of the scale of social financing in China is generally stable, but there is progress in stability. The stock of social financing is increasing, and the overall social financing environment has improved. After the preliminary test, it was found that the original data were all unstable. In order to reduce the fluctuation between the data and make the sequence values tend to be stable, the first-order difference processing was carried out on all variables.

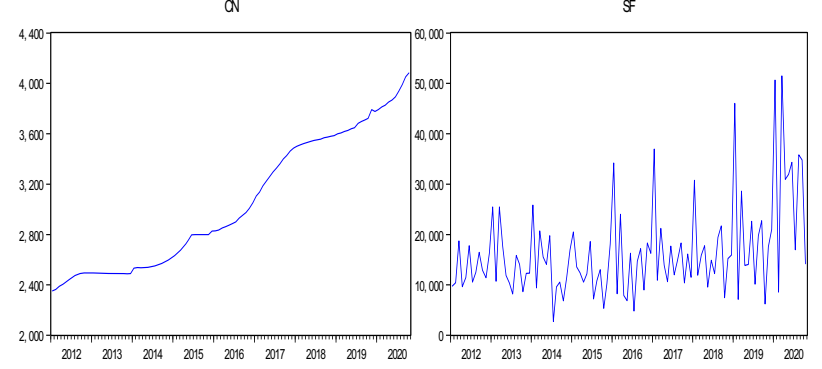

Fig 1 Time sequence diagram of each variable

\subsection{Descriptive statistical analysis.}

Descriptive statistical analysis data of $\mathrm{CN}$ and $\mathrm{SF}$ variables are shown in Table 1 . It can be seen from the table that the sample standard deviations of $\mathrm{CN}$ and SF are relatively large during 2012-2020, indicating that both variables have a large degree of dispersion and the data fluctuate greatly. From the point of view of the maximum and minimum values, the range of variables is large. From 2012 to 2020, CN and SF have undergone great changes, and from the point of view of mean and median, the changes of data mainly show an increasing trend.

Table1 Descriptive statistical results of each variable

\begin{tabular}{|c|c|c|c|c|c|}
\hline index & Mean & Media & Max & Min & Std. \\
\hline CN & 3050 & 2880 & 4082 & 2352 & 523 \\
\hline SF & 16512 & 14124 & 51492 & 2731 & 9144 \\
\hline
\end{tabular}

\subsection{Model construction}

Selecting multiple variables that influence each other to establish a regression model will increase the difficulty to infer and estimate them, but the non-structural econometric model using vector autoregressive model (VAR model) can accurately grasp the dynamic relationship among the variables. In this paper, we study the listed company on the dynamic relationship between quantity and social financing scale, need the equal treatment to each variable, taking the form of equations of multiple, no additional traditional default constraint in the model, each of the endogenous variable of the model equations all the endogenous variable lag item to return, so as to estimate the dynamic relationship between all the endogenous variables. The expression of the VAR model is as follows:

$$
\begin{gathered}
y_{t}=\sum_{i=1}^{n} A_{i} y_{t-i}+\varepsilon_{t} \quad(t=0, \pm 1, \pm 2 \cdots) \\
\text { In } y_{t}=\left(y_{1 t}, y_{2 t}, \cdots, y_{n t}\right) \quad(t=1,2, \cdots, T), \mathrm{n} \times 1 \text { dimensional }
\end{gathered}
$$
random variable is the coefficient matrix, $A_{i}$ is the coefficient matrix.

\section{Model estimation}

\subsection{Stationary test of variables}

Due to the non-stationary data to avoid "false return", using the ADF unit root test to $\mathrm{CN}$, SF, time series stationarity test data, but not through, $\mathrm{CN}, \mathrm{SF}$ are non-stationary series, to first order difference of two variables, first order difference sequence of DCV respectively, after the DSF, again carries on the ADF unit root test, The results show that $\mathrm{DCN}$ is stable at the significance level of 5\%, DSF is stable at the significance level of $1 \%$, and both of them are first-order integrated sequences, and there may be a co-integration relationship between them.

Table2 ADF test results

\begin{tabular}{|c|c|c|c|}
\hline variable & ADF statistics & Prob & result \\
\hline $\mathrm{CN}$ & 1.453975 & 0.999 & non-stationary \\
\hline SF & 3.006802 & 1.000 & non-stationary \\
\hline DCN & -3.221187 & 0.021 & stationary \\
\hline DSF & -9.971024 & 0.000 & stationary \\
\hline
\end{tabular}

\subsection{Johansen co-integration test}

Then, Johansen test method was used to test whether there is a long-term equilibrium relationship between $\mathrm{CN}$ and SF. The results are shown in Table 3. At the significance level of $5 \%$, there is a co-integration relationship between $\mathrm{CN}$ and $\mathrm{SF}$.

Table3 Johansen co-integration test results

\begin{tabular}{|c|c|c|c|}
\hline \multicolumn{3}{|l|}{ Unrestricted Cointegration Rank Test (Trace) } \\
\hline $\begin{array}{c}\text { Hypothesized } \\
\text { No. of CE(s) }\end{array}$ & Eigenvalue & $\begin{array}{c}\text { Trace } \\
\text { Statistic }\end{array}$ & Prob.** \\
\hline None* & 0.260002 & 34.495 & 0.0000 \\
\hline At most 1* & 0.030116 & 3.182 & 0.0745 \\
\hline $\begin{array}{l}\text { Trace test indicates 1 cointegrating eqn(s) at the } 0.05 \text { level } \\
\text { *denotes rejection of the hypothesis at the 0.05 level } \\
* * \text { MacKinnon-Huag-Michelis (1999) p-values }\end{array}$ \\
\hline
\end{tabular}

\subsection{Granger causality test}

Further, Granger causality test is used to test whether there is a causal relationship between $\mathrm{CN}$ and SF in the sense of econometrics. The test results are shown in Table 4. CN is the Granger cause of the change of SF, but 
$\mathrm{SF}$ is not the Granger cause of the change of $\mathrm{CN}$, that is, the change of $\mathrm{CN}$ will cause the change of SF, but the change of total SF will not cause the change of $\mathrm{CN}$. This may be because the change of the number of listed companies will lead to the change of the number of social direct financing entities, which will affect the direct financing demand, and then affect the change of the overall scale of social financing. In addition to direct financing, social financing also includes loans, bonds, bills of exchange and other financing, so changes in the scale of social financing do not necessarily lead to changes in the number of listed companies.

Table 4 Granger causality test results

\begin{tabular}{|l|l|l|}
\hline Null Hypothesis: & Prob. & result \\
\hline CN does not Granger Cause SF & 0.0073 & reject \\
\hline SF does not Granger Cause CN & 0.4318 & accept \\
\hline
\end{tabular}

\subsection{Judgment of lag order}

In this paper, the information criterion was used to set the lag order as 4 for testing, and the results were shown in Table 5. According to the test result under AIC information criterion, the optimal lag order of the VAR model was 3, so the VAR (3) model was established.

Table5 Determination of lag order

\begin{tabular}{|c|c|c|c|c|c|}
\hline Lag & LR & FPE & AIC & SC & HQ \\
\hline 0 & NA & $4.44 \mathrm{e}+10$ & 30.2 & 30.2 & 30.2 \\
\hline 1 & 99.1 & $-1.75 \mathrm{e}+10$ & 29.3 & 29.4 & 29.3 \\
\hline 2 & 25.4 & $1.45 \mathrm{e}+10$ & 29.1 & $29.3 *$ & 29.2 \\
\hline 3 & $11.9 *$ & $1.39 \mathrm{e}+10^{*}$ & $29.0^{*}$ & 29.4 & $29.2^{*}$ \\
\hline 4 & 5.1 & $1.42 \mathrm{e}+10$ & 29.1 & 29.5 & 29.2 \\
\hline
\end{tabular}

\subsection{Parameter estimation and stationarity test}

\subsubsection{Parameter estimation of VAR3) model}

According to the information criteria mentioned above, the VAR model with a lag of 3 orders was selected in this paper. It can be seen from the estimation results that the goodness of fit of the two equations, SF and CN, is good, indicating that there is a close relationship between $\mathrm{CN}$ and SF. The estimated results obtained from the VAR (3) model are shown in Table 6.

Table6 Parameter estimation results of VAR (3) model

\begin{tabular}{|c|c|c|}
\hline & DCN & DSF \\
\hline DCN(-1) & 0.345133 & -43.98614 \\
\hline DCN(-2) & 0.226147 & 184.1085 \\
\hline DCN(-3) & 0.214780 & -182.6202 \\
\hline DSF(-1) & -0.000225 & -0.925193 \\
\hline DSF(-2) & -0.000178 & -0.44879 \\
\hline DSF(-3) & $-7.78 \mathrm{E}-05$ & -0.052839 \\
\hline
\end{tabular}

\begin{tabular}{|c|c|c|}
\hline $\mathrm{C}$ & 3.977760 & 927.0348 \\
\hline $\mathrm{R}^{2}$ & 0.402925 & 0.583005 \\
\hline
\end{tabular}

\subsubsection{Model stability test}

The stability of the VAR model is an important basis for subsequent analysis. After the establishment of the VAR (3) model, the new VAR model is tested for its stationarity. If the points represented by the inverse of the roots of AR characteristic polynomials are all within the unit circle, the established VAR (3) model is stable. As can be seen from Figure 2, the lag structure test shows that the roots of all AR characteristic polynomials are all within the unit circle. Thus, the established VAR (3) model is stable.

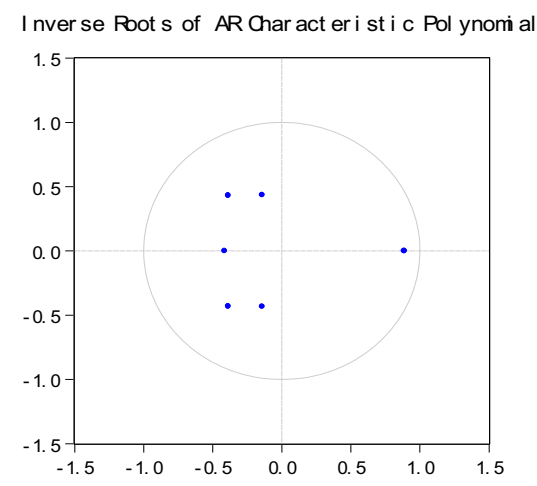

Fig 2 Stationary test of VAR (3) model

\section{Model Analysis}

\subsection{Impulse response analysis}

Fig. 3 respectively shows the responses of SF and $\mathrm{CN}$ to different impact variables when an impact of one standard deviation is applied to them at the $95 \%$ confidence level. As can be seen from Fig. 3, there is no longitudinal intercept in the disturbance analysis, and such features as the figure indicate that $\mathrm{CN}$ has no obvious immediate influence on SF. In the face of the external random impact of $\mathrm{CN}$, SF will not change greatly in the immediate period and has a slight trend of decline, but will gradually rise as time goes on. It will rise to the peak near the third stage, and then show a trend of decline and then rise after reaching the peak, and gradually weaken and converge to zero after the fifth stage. In addition, the $\mathrm{CN}$ of $\mathrm{SF}$, the impact of the positive response is not obvious higher than negative response, indicating that the current $\mathrm{CN}$ increase the overall is not obvious positive stable positive influence on SF, may also be implied in the increase of the amount of the lack of qualitative, the ranks of the listed company of the growing expansion of SF, may not fully play a role. However, from the perspective of the overall response of $\mathrm{SF}$ to $\mathrm{CN}$, the response degree of SF is relatively large, indicating that $\mathrm{CN}$ does affect $\mathrm{SF}$ to some extent. 


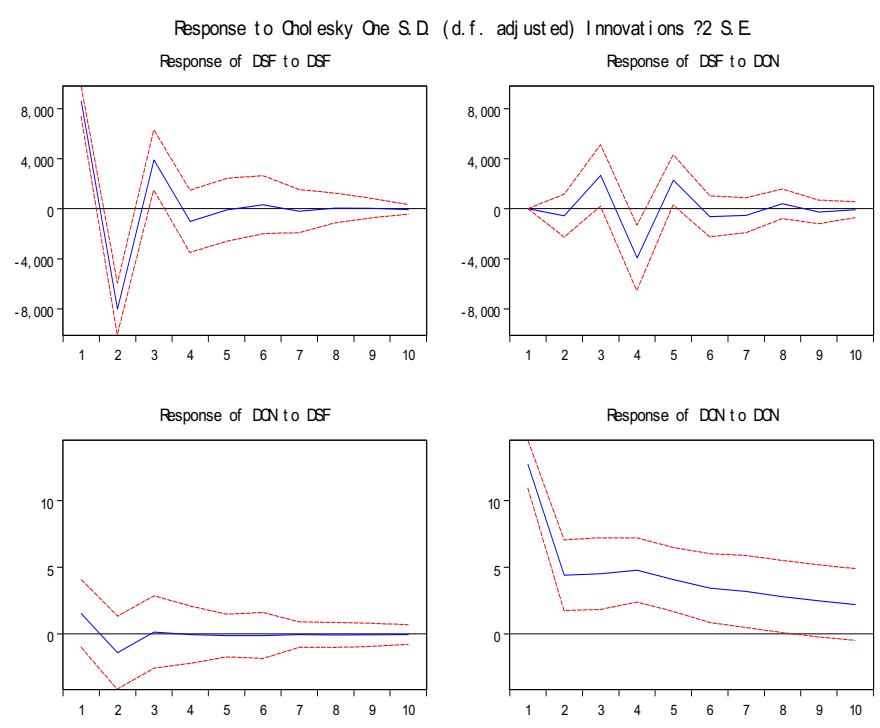

Fig 3 Impulse response diagram

\subsection{Variance decomposition}

The interpretation degree of $\mathrm{CN}$ to $\mathrm{SF}$ index was further analyzed through variance decomposition, and the variance decomposition results were shown in Table 7. Results can be obtained by variance decomposition, to explain changes in the initial state of SF, on their own level of $98.6 \%, \mathrm{CN}$ interpretation of SF, change degree was $1.43 \%$, with the increase of nper, $\mathrm{CN}$ explanation of $\mathrm{SF}$, change degree also gradually increase, the second to the third phase of the stage and the third to the fourth increase obviously, explain degree increased by $6 \%$ and $8 \%$ respectively, The contribution rate remained relatively stable after the lag period of 5 , and the contribution rate of the lag period of 10 reached $19.2 \%$, which was about 19 times of the explanation degree of the first period. In the variance of SF equation, the contribution degree caused by its own disturbance or impact decreases with the increase of lag periods, but it keeps a high contribution rate, and the contribution rate is still $80.8 \%$ for 10 lag periods. This indicates that although the change of SF mainly comes from its own stock, if the influence of SF itself is excluded, the social financing scale in the lag period is mainly affected by the change of $\mathrm{CN}$, and with the increase of the number of periods, the influence becomes more and more obvious and the influence becomes more and more powerful.

Table 7 Variance decomposition table

\begin{tabular}{|c|c|c|c|}
\hline Period & S.E. & DCN & DSF \\
\hline 1 & 8585.153 & 1.434996 & 98.56500 \\
\hline 2 & 11755.21 & 2.426520 & 97.57348 \\
\hline 3 & 12669.86 & 8.132531 & 91.86747 \\
\hline 4 & 13303.90 & 16.51779 & 83.48221 \\
\hline 5 & 13499.60 & 18.84225 & 81.15775 \\
\hline 6 & 13517.40 & 18.97393 & 81.02607 \\
\hline 7 & 13528.97 & 19.10253 & 80.89747 \\
\hline 8 & 13534.67 & 19.17066 & 80.82934 \\
\hline 9 & 13537.21 & 19.19822 & 80.80178 \\
\hline 10 & 13537.55 & 19.20131 & 80.79869 \\
\hline
\end{tabular}

\section{Conclusions and Suggestions}

Based on the empirical analysis of VAR (3) model, this paper draws the following conclusions: (1) The increase in the number of listed companies will boost the expansion of social financing scale, but the expansion of social financing scale will not necessarily lead to the corresponding expansion of the ranks of listed companies. Therefore, the expansion of the ranks of listed companies does promote the expansion of social financing scale, but it is not the only choice. (2) The number of listed companies has an exact impact on the scale of social financing, but the immediate positive impact is not obvious, indicating that the current development of China's stock market "quantity increase" may also imply a "qualitative shortage", the growth of listed companies to boost the scale of social financing still need to be further explored. (3) The change of social financing scale is strongly influenced by its own disturbance, but the number of listed companies is also an important influencing factor, and with the increase of the number of periods, the influence is more and more obvious and the influence is stronger.

There is a close relationship between the number of listed companies and the scale of social financing in China. The expansion of listed companies has an important influence on improving the efficiency of capital allocation, increasing the scale of social financing and improving the financing structure. But at the moment, an increase in the number of listed companies in China to promote social financing scale efforts still need to further strengthen, the author thinks that, in the critical period of deepening financial supply side structural reform, must further improve the multi-level capital market system with Chinese characteristics, not only to strengthen team of listed companies, to improve the quality of listed companies, strengthen the development of direct financing, Thus, to expand the scale of direct financing, increase the proportion of direct financing, and realize the "increase in quantity" and "qualitative improvement" of social financing can better serve the development of 
the real economy.

\section{References:}

1. Li Yuan, Wang Jing, Wu Fan, Duan Weiyue. Research on the relationship between social financing structure and industrial structure $[\mathrm{J}]$. North China Finance, 2020(02):21-27.

2. Liu Xiaoyu, Peng Yingqi. An empirical analysis of the relationship between social financing structure and industrial structure [J]. Statistics and Decision, 2019, 35(05):171-173.

3. Liu Dehong, Li Yamin. The influence of the development of social financing system on the financing constraints of enterprises [J]. Beijing Jiaotong University (Social Science Edition),2020, 19(03):54-63.

4. Wang Dingxiang, $\mathrm{Xu}$ Ruiheng. Research on the Threshold Effect of Stock Market Development on Economic Growth in China: An Empirical Analysis Based on the Panel Data of Province [J].Dong Yue Collections, 2019, 40(08):50-61+191-192.

5. Zhang Zhe, Xu Ling. Research on the influencing factors of social financing scale in China in the new era [J]. Contemporary Economic Management, 2019, 41(05):92-97. 